\title{
Statistical Comparison of the Hardness and Scratch-Resistance of the PMMA Polymers Used in Orthodontic Appliances
}

\author{
Ivo Domagała', Leszek Gil2 ${ }^{*}$, Marcel Firlej', Daniel Pieniak², \\ Jarosław Selech ${ }^{3}$, Dawid Romek ${ }^{3}$, Barbara Biedziak'
}

1 Department of Craniofacial Anomalies, University of Medical Sciences, Poznan, ul. Bukowska 70, 60-812 Poznań, Poland

2 University of Economics and Innovations in Lublin, Faculty of Transport and Computer Science, 4 Projektowa st., 20-209 Lublin, Poland

3 University of Technology, Faculty of Civil and Transport Engineering, 3 Piotrowo st., 60-965 Poznań

* Corresponding author's e-mail: leszek.gil@wsei.lublin.pl

\begin{abstract}
The paper presents the studies and results of the Shore hardness and scratch test of polymer materials used in medical devices. Polymers of organic PMMA (poly(methyl methacrylate)) origin for the manufacture of orthodontic appliances were tested. Samples of test materials differed in manufacturing technology. The surface functional properties of four materials were compared. Hardness tests were performed with the Shore D hardness test method. The scratch test was done with a Rockwell diamond cone indenter. The hardness was also calculated from the scratch test. Shore's highest hardness was demonstrated in 1A material. But the differences in Shore's hardness were small. Larger differences between the tested materials were shown in the scratch test than in the Shore hardness test. The lowest residual scratch depth (Rd) was obtained for 1A material. 3A material had the highest scratch hardness.
\end{abstract}

Keywords: orthodontic appliances, PMMA, hardness; scratch resistance.

\section{INTRODUCTION}

Polymer plastics constitute a large part of the products used to manufacture medical devices [1]. Solid polymer elements and polymer coatings are used $[2 \div 4]$. The use of polymers is common, e.g. as thin packaging films and waste bags [5]. Scientific research includes issues related to the maintenance and operation of polymer medical devices [6,7] and orthodontic appliances [8,9]. The strength, durability and reliability of polymer based medical devices studies are utilitarian $[10 \div 16]$. Tribological wear is a common problem in engineering $[17 \div 20]$. This phenomenon also applies to medical devices [21]. One of the factors limiting durability and reliability of polymerbased medical devices in clinical situation is tribological wear of medical devices surfaces $[22 \div 27]$.
Poly(methyl methacrylate) (PMMA) has been widely used in different fields of healthcare. It is used in orthopedics, prosthodontic dentistry and for many other medical devices $[28,29]$. The polymer PMMA is one of most popular thermoplastics due to its physical and mechanical properties: low affectation by ultraviolet radiation, low elongation at break, highly scratch resistant, it exhibits low moisture and water absorbing capacity, good dimensional stability, high Young's modulus and hardness, high volume/weight ratio [30]. PMMA to medical devices applications is characterized by low sorption and solubility in saliva and other fluids, stable colour, and appropriate hardness [31].

Orthodontic splints made of PMMA are used to treat involuntary tooth compression and gnashing (Fig. 1), also orthodontic appliances including 

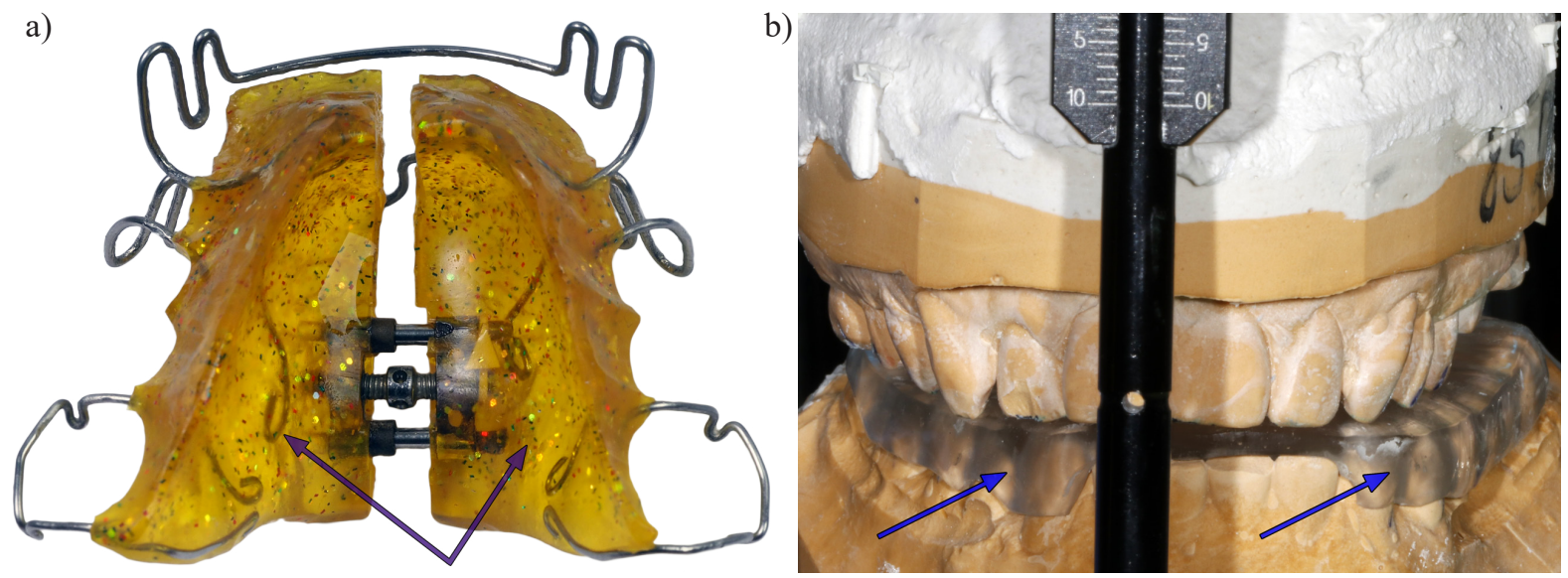

Fig. 1. Orthodontic appliance (a) and splint (b) (polymer parts are indicated by arrows)

biomechanical, used to treat malocclusion, are made of PMMA (Fig. 1). Researchers found that deformation and abrasion were observed where human teeth contacted polymeric orthodontic appliances. It was shown that the degree of damage to orthodonic appliances was correlated with maximum muscle activity during sleep [32]. Such damage limits the effect of treatment and the durability of medical devices.

Polymer material hardness is a measure of resistance to contact concentrated forces. Such forces may arise in cases of orthodontic treatment of involuntary clamping of teeth. The action of these forces can lead to permanent damage by local deformation of the material of orthodontic appliances in the place of impact of concentrated biomechanical forces, e.g. as a result of contact with teeth cusps. Therefore, hardness as a mechanical property of the material is a functional feature of orthodontic appliances. In cases where teeth grinding (bruxism) or in other cases, e.g. normal and tangential occlusal forces from nodules and edges of the teeth, there is a tribological wear of the orthodontic appliances surface.

Tribology of polymers is different from tribology of metals for many reasons. In contrast to metals, polymers are visco-elastic and their properties are dependent on time [33]. Scratch test has often used to give a guide to the abrasive wear resistance of polymers [34]. In a clinical situation, scratches may be caused by sharp unevenness at the edge of the teeth, these unevenness may arise, among others, as a result of chipping the enamel in the incisal edge of the incisors in the disease. Another cause of unevenness is inaccurate enamel preparation and cavity filling. Such a situation contributes to the formation of inequalities along the filling outline [35].

The aim of the study was an experimental comparative assessment of hardness and scratch resistance of four selected polymer materials based on PMMA resins, which are used in the manufacture of orthodontic appliances.

\section{MATERIALS AND TEST METHODS}

\section{Speciments preparation}

Four commercial materials were used in the study. NextDent Ortho Rigid material (VertexDental B.V., The Netherlands), based on acrylic resins, code 1A. Material 1A is biocompatible and developed for the production of orthodontic components in 3D printing technology. Erkocryl (ERKODENT Erich Kopp GmbH, Germany) is an acrylic plastic material ( $2 \mathrm{~A}$ code), defined by the manufacturer as a stable and hard material. 2A material is intended for the production of orthodontic components. Vertex Orthoplast (Vertex Dental B.V., The Netherlands) is a polymer material based on acrylic resin, intended for the production of orthodontic appliances. This material is suitable for the bulk technique and crushed dough [36]. Vertex Orthoplast is made as colourless and 18 colour dies are available. Vertex Orthoplast material of two different colours was used for the tests - dark blue (marked with the code $3 \mathrm{~A}$ ) and orange (marked with the code $4 \mathrm{~A}$ ) [37]. The samples used in the study were made in the form of rectangular orthodontic tiles with nominal dimensions of $30 \mathrm{~mm}$ wide, $2.5 \mathrm{~mm}$ thick (scratch test) and $6 \mathrm{~mm}$ (Shore hardness 
Table 1. Specifications of acrylic resin based materials used in this study

\begin{tabular}{|c|c|c|c|c|}
\hline Material & Batch number & Expiration date & Code & Material composition \\
\hline OrthoRigid & XK445N01 & $2019-11$ & $1 \mathrm{~A}$ & $\begin{array}{c}\text { Methacrylic oligomers, Phospine } \\
\text { oxides, colorants and pigments }\end{array}$ \\
\hline Erkocryl & 11198 & $2022-04$ & $2 \mathrm{~A}$ & Polymethylmethacrlat \\
\hline Vertex & XH212P05 & $2023-11$ & $3 \mathrm{~A}$ & \multirow{2}{*}{$\begin{array}{c}\text { Methyl Imethacrylate, Ethyl- } \\
\text { englycol dimethacrylate } \\
\text { N,N-Dimethyl-p-toluidine }\end{array}$} \\
\hline Vertex & XH153L03 & $2023-10$ & $4 \mathrm{~A}$ & \multirow{2}{*}{}
\end{tabular}
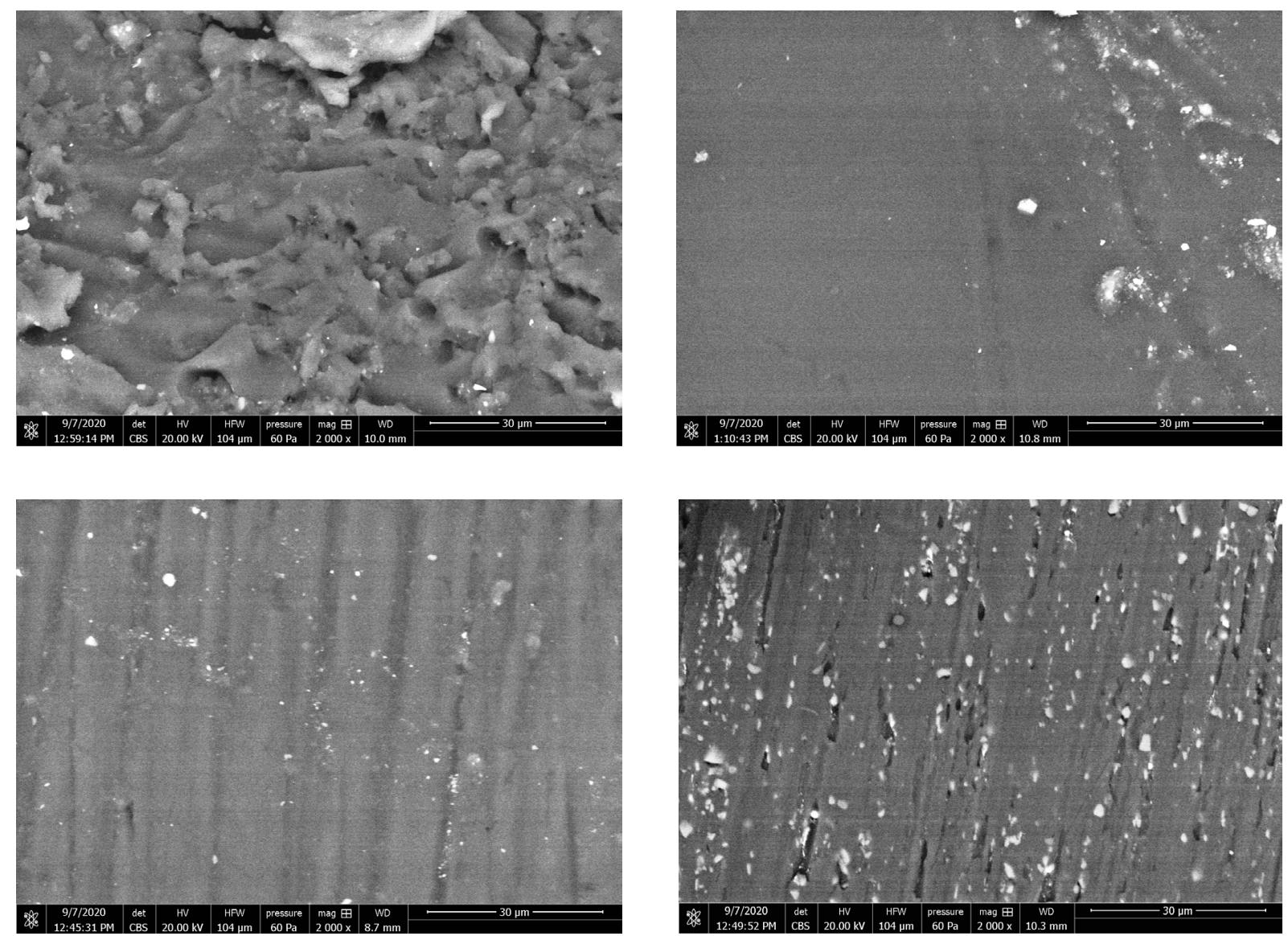

Fig. 2. SEM micrographs of surface of tested materials (mag. 2000×)

test), $50 \mathrm{~mm}$ long. The specimens were polished with abrasive discs (granulation P600, P1200, P2400 and synthetic polishing pad) on a single wheel grinder and polisher Saphir 550 (ATM Gmbh, Mammelzen, Germany) equipment and then cleaned in water. Specimens were aging in artificial saliva bath at $37 \pm 1^{\circ} \mathrm{C}$ in temperature chamber Q-Cell (Pol-Lab, Wilkowice, Poland). Five samples were made of each type of hardness test material and the same number for scratch resistance tests. Observations were made on a scanning electron microscope (SEM) Quanta FEG 650. The parameters of the tested materials are shown in Table 1. SEM images of the tested materials are shown in Figure 2.

\section{Shore hardness tests}

The hardness test was carried out using a Shore apparatus on the "D" scale, designed for testing hard and very hard plastics according to PN-EN ISO 868: 2005. The indenter test load on the Shore D method was $44450 \mathrm{mN}$ (5000 g). The scale ranges from 0 to 100 Shore degrees. This method involves measuring the size of the indentation in the material of the steel indenter which has a conical end. The measure of hardness is the value inversely proportional to the size of the depression created by the force of $44450 \mathrm{mN}$ [38]. The Shore method allows testing the hardness of polymeric orthodontic materials based on PMMA 


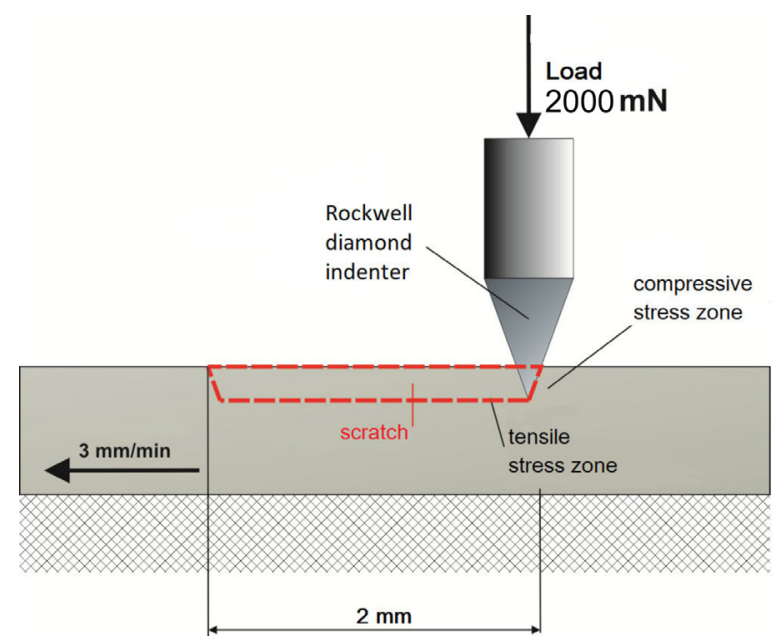

Fig. 3. Schematics of the scratch resistance test

resins [31]. In the tests a Shore HPE II durometer (Bareiss Prüfgerätebau $\mathrm{GmbH}$, Oberdischingen, Germany) was used, mounted on BS 61 II test stands (Bareiss Prüfgerätebau GmbH, Oberdischingen, Germany).

\section{Scratch resistance test}

The scratch resistance test was carried out on the Micro Scratch Tester (MST, Anton Paar GmbH, Ostfildern, Germany) according to the diagram presented in Figure 3. A Rockwell indenter in the form of a diamond cone with a rounding radius of $100 \mu \mathrm{m}$ was used. The indenter was loaded to a constant normal force $(F n)$ of $2 \mathrm{~N}$ at a speed of $5 \mathrm{~N} / \mathrm{s}$. Then a $2 \mathrm{~mm}$ scratch was carried out at a speed of $3 \mathrm{~mm} / \mathrm{min}$.

During the test, the following values were recorded with a frequency of $30 \mathrm{~Hz}$ : friction coefficient $(\mu)$, friction force $(F t)$, indenter penetration depth $(P d)$ and residual depth after scratching $(R d)$. "Prescan" and "postscan" were made to identify the surface profile. The scratch was assessed using an optical microscope connected to the MST device. This device allowed to measure the width of the SW crack (Fig. 4).

Based on the results of the crack width tests, the "scratch hardness" Hs was calculated. The calculation of $H s$ was made according to the formula contained in [39]:

$$
\mathrm{Hs}=\frac{4 \cdot \mathrm{x} \cdot \mathrm{Fn}}{\pi \cdot \mathrm{SW}^{2}}
$$

where: $H s$ - scratch hardness in N/ $\mathrm{mm}^{2}, F n$ - normal force in N, $S W$ - scratch width in $\mathrm{mm}$, $x$ - parameter accepted in the range of $1 \div 2$ $(\mathrm{x} \approx 2$ is for rigid plastic materials, $\mathrm{x}>1$ for viscoelastic olastic materials), in this work the value 1 according to [40] was adopted.

\section{Statistical analysis}

Descriptive statistics of the test results were calculated, statistical measures of location and variability of measures. Then, the statistical distribution normality, analysis of variance and post hoc tests were performed.

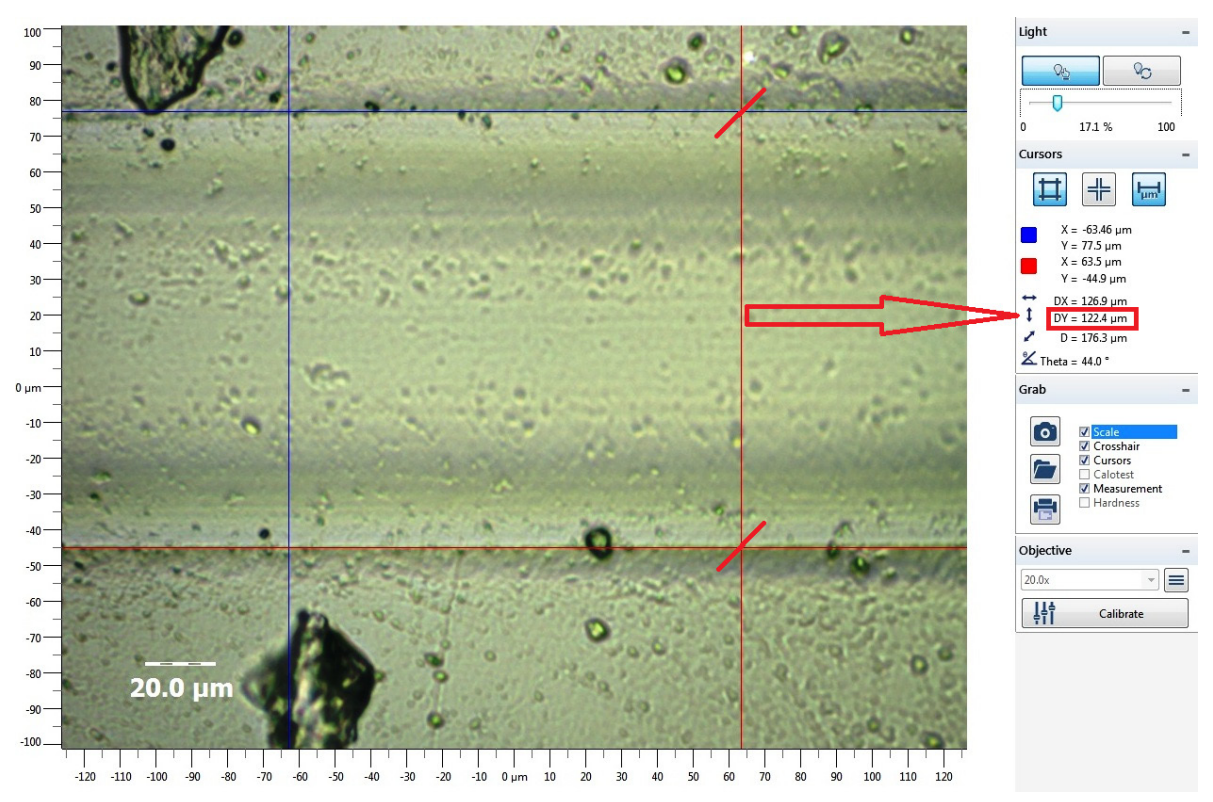

Fig. 4. Measurement of the scratch width using an optical microscope (material 2A) 
One of the most important distributions of random variables is the normal distribution, also called the Gauss distribution [41]. To measure the parameters of the representative distribution of the normal distribution for the population - the probability that the sample comes from a population with a normal distribution, the ShapiroWilk test was performed. The Shapiro-Wilk test is a test of analysis of variance for the hypothesis of normality of distribution, in which the test statistics is the ratio of the square of the linear combination of positional statistics to the assessment of variance [42]. In order to determine the compliance of test results with the normal distribution, the value of Saphiro-Wilk (W) statistics was calculated. The test adopted the significance level $\alpha=0.05$ and the null hypothesis $H_{0}$ : the test results have a normal distribution (for $p>\alpha$ ) and the alternative hypothesis $H_{1}$ : the test results do not have a normal distribution (for $p<\alpha$ ). The higher the statistic value, the closer the fit to the normal distribution is.

Analysis of variance (ANOVA) is a parametric tool enabling comparison of average values. In the present study, one-way analysis of variance (analysis for one variable) for four groups (four materials) may apply [43].

ANOVA is a parametric test that can be performed provided that the following assumptions are met [43]:

- quantitative variable is analyzed,

- distribution of the dependent variable in the analyzed groups is a normal distribution,

- distribution of the dependent variable in the analyzed groups have a homogeneous variance.

In this work, the first assumption is met for all test results, because they are quantitative. The second assumption is met for all groups of Shore hardness test results. Levene and Brown-Forsythe tests were used to analyze the homogeneity of variance. The null $H_{0}$ hypothesis was adopted: variances in different groups are homogeneous (for $p>0.05$ ) and the alternative $H_{1}$ hypothesis: variances in different groups are heterogeneous (for $p \leq 0.05$ ). The fulfillment of the null hypothesis is demonstrated by the value of the $F$ test close to 1 .

The "post hoc" test was carried out to assess the differences between the Shore hardness results of the tested materials. Tukey's HSD test for equal counts was chosen, based on the analysis of contrasts in groups of measurement results, i.e. honest significant differences in groups (HSD) [44]. The differences between the results of hardness measurements are indicated by the values of significance of $p$ differences. The $p$ values below the assumed level $(p<0.05)$ indicate significant differences between the parameters of results in grups.

\section{STATYSTICAL ANALYSIS OF TEST RESULTS}

\section{Shore hardness test results}

Descriptive statistics of the Shore hardness test results are presented in Table 2. The table contains statistical measures of location (arithmetic mean, median) and variability measures (minimum and maximum values, standard deviation, coefficient of variation). Similar results of Shore hardness testing of materials were obtained. Material $1 \mathrm{~A}$ had the highest Shore hardness and material 2A the lowest.

The hardness test results have been grouped for further analysis depending on the material and presented assessment of normality of distribution. The results of the Shapiro-Wilk test are presented in Table 3. In the light of the statistical calculations presented in Table 3, Shore's hardness test results have a normal distribution in all groups.

Assessment of significance of differences included analysis of variance and "post hoc" test. Analysis of variance results presented in Table 4. Table 4 includes: source of variation, mean value of the sum of squares of deviations describing variations between groups (MS Effect), mean value of the sum of squares of deviations describing

Table 2. Descriptive statistics of hardness results using the Shore method D

\begin{tabular}{|c|c|c|c|c|c|c|c|}
\hline Sample & $\begin{array}{c}\text { N (number of } \\
\text { measurements) }\end{array}$ & Mean & Median & Min & Max & Std. Dev. & Var. Coaf. \\
\hline 1A & 20 & 80.38 & 80.80 & 73.20 & 82.40 & 2.16 & 2.69 \\
\hline 2A & 20 & 78.02 & 78.10 & 69.00 & 82.80 & 3.50 & 4.48 \\
\hline 3A & 20 & 79.56 & 79.70 & 77.10 & 81.90 & 1.50 & 1.88 \\
\hline 4A & 20 & 78.81 & 78.80 & 75.50 & 81.50 & 1.92 & 2.44 \\
\hline
\end{tabular}


Table 3. Shapiro-Wilk $W$ and $p$ value of Shore hardness test results

\begin{tabular}{|c|c|c|}
\hline Group (material) & W & p \\
\hline 1A & 0.7956 & 0.0740 \\
\hline $2 \mathrm{~A}$ & 0.9360 & 0.2016 \\
\hline 3A & 0.9231 & 0.1138 \\
\hline 4A & 0.9408 & 0.2406 \\
\hline
\end{tabular}

Table 4. Results of variance homogeneity tests

\begin{tabular}{|c|c|c|c|c|}
\hline \multicolumn{5}{|c|}{ Test Levene } \\
\hline Source of variance & MS - Effect & MS Error & F & p \\
\hline Group (material) & 7.668 & 2.303 & 3.329 & 0.024 \\
\hline \multicolumn{5}{|c|}{ Brown-Forsythe } \\
\hline Source of variance & MS - Effect & MS Error & F & p \\
\hline Group (material) & 8.011 & 2.412 & 3.321 & 0.024 \\
\hline
\end{tabular}

Table 5. Tukey test results

\begin{tabular}{|c|c|c|c|c|}
\hline Groups & $\{\mathbf{1}\}-\mathbf{M}=\mathbf{8 0 . 3 8 0}$ & $\{\mathbf{2}\}-\mathbf{M}=\mathbf{7 8 . 0 1 5}$ & $\{\mathbf{3}\}-\mathbf{M}=\mathbf{7 9 . 5 6 5}$ & $\{\mathbf{4}\}-\mathbf{M}=\mathbf{7 8 . 8 0 5}$ \\
\hline 1A $\{1\}$ & & 0.0131 & 0.7038 & 0.1678 \\
\hline 2A $\{2\}$ & 0.0131 & & 0.1789 & 0.7236 \\
\hline 3A $\{3\}$ & 0.7038 & 0.1789 & & 0.7467 \\
\hline 4A $\{4\}$ & 0.1678 & 0.7235 & 0.7467 & \\
\hline
\end{tabular}

variations within the samples (MS Error), test value $(F)$, probability level $(p)$. The red values indicate the rejection of the null hypothesis. The results of homogeneity tests of variance allow the null hypothesis to be rejected.

The "post hoc" test result presented in Table 5. The $p$ values below the assumed level $(p<$ 0.05 ) indicate significant differences between the parameters of Shore's hardness results. The values indicating significant differences are marked in red. The results of the post hoc test show significant differences between the hardness results of materials $1 \mathrm{~A}$ and $2 \mathrm{~A}$.

\section{Scratch test results}

\section{Result of crack geometry and friction coefficient tests}

Figure 5 shows the scratch on the surface of material 1A. Similar shapes of scratches were obtained on the surfaces of samples of all tested materials. No observed cohesive failures, including microcracks of tested materials.

The geometry of the scratches was analyzed. The residual scratch depth $(R d)$ was determined. Averaged curves were determined for each of the

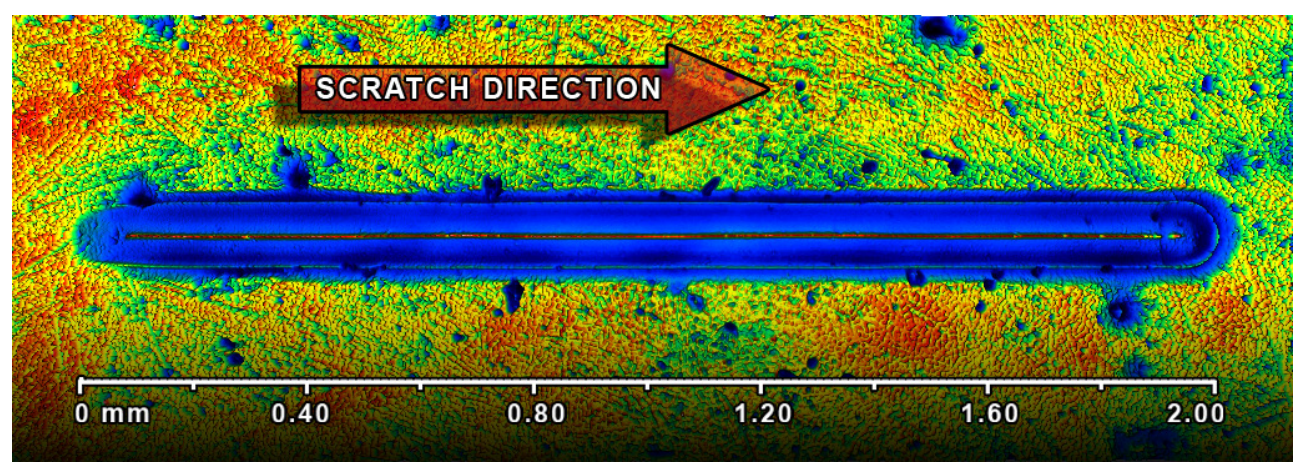

Fig. 5. Test scratch on the surface of the material 1A 


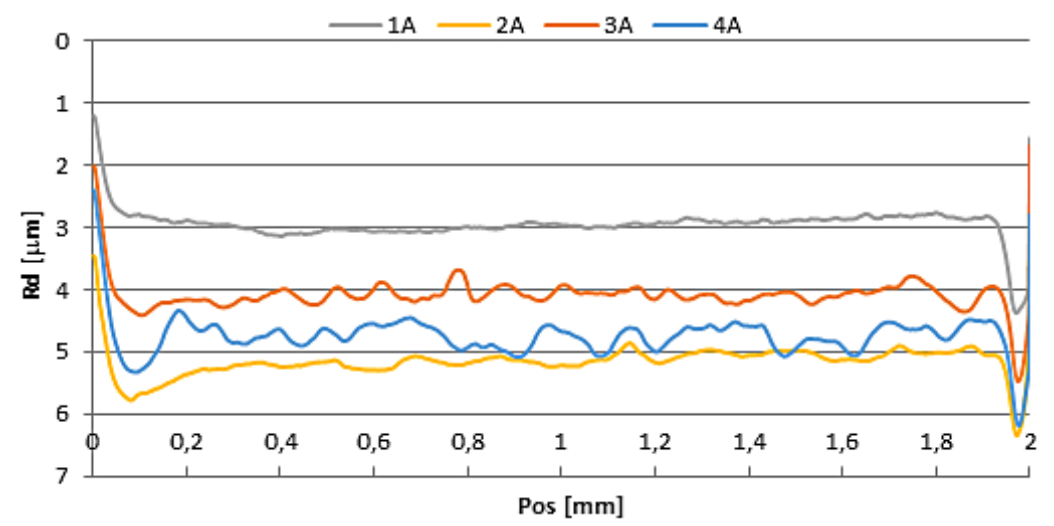

Fig. 6. Average courses of residual scratch depth on sample surfaces

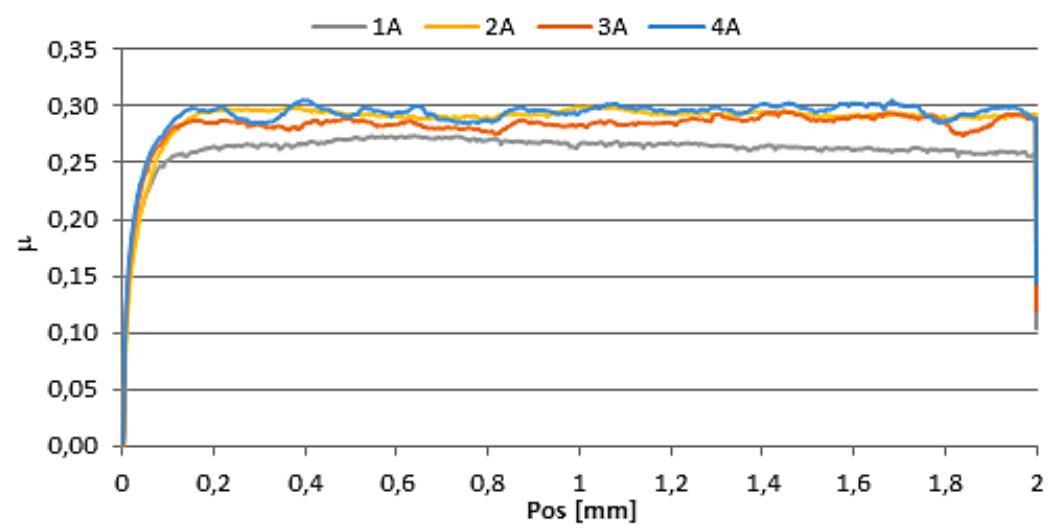

Fig. 7. Average runs of the friction coefficient $\mu$

tested materials. The results of testing the size of $R d$ are summarized in Figure 6. The highest scratch depth was observed in the case of $2 \mathrm{~A}$. It is a material that has the lowest Shore hardness. The smallest residual scratch depth was obtained for 1 A material.

Figure 6 presents further test results relevant to the scratch resistance of the surface of the polymer materials tested. Figure 7 presents graphs of friction coefficient $(\mu)$ as a function of indenter displacement. The friction coefficient is the ratio of the normal (active) force to the surface whose vector coincides with the main axis of the indenter, to the friction force which is the reaction (reactive) force whose vector is tangent to the friction surface. The high value of the friction coefficient indicates a high friction resistance $[28,45]$. In the presented research similar average courses of the friction coefficient were obtained. The highest values of the friction coefficient were obtained on the surface of the material $4 \mathrm{~A}$, a similar value was shown on the surface of the material 2A. The lowest value of the friction coefficient was recorded in the case of 1A material, which had the lowest residual scratch depth and the highest Shore hardness.

\section{Scratch hardness results}

In the case of the scratch hardness test results, the same statistical analysis was performed as for the Shore hardness test results. Table 6 presents descriptive statistics of the results of scratch hardness tests $(H s)$.

The results of the Shapiro-Wilk test regarding scratch hardness are presented in Table 7. In the light of the statistical calculations presented in Table 7, the results of the scratch hardness tests have a normal distribution in all groups.

Table 8 presents the results of the tests for homogeneity of variance of scratch hardness results from a scratch test. The results of homogeneity tests of variance allow to reject the hypothesis on the homogeneity of variance in groups.

Table 9 presents the results of the Tukey HSD statistical test. The differences between the results 
Table 6. Descriptive statistics of scratch hardness results (Hs)

\begin{tabular}{|c|c|c|c|c|c|c|c|}
\hline Sample & $\begin{array}{c}\text { N (number of } \\
\text { measurements) }\end{array}$ & Mean & Median & Min & Max & Std. Dev. & Var. Coaf. \\
\hline 1A & 25 & 166.45 & 167.04 & 158.21 & 174.30 & 4.27 & 2.57 \\
\hline 2A & 25 & 172.77 & 173.73 & 168.68 & 177.52 & 2.94 & 1.70 \\
\hline 3A & 25 & 196.12 & 196.04 & 187.40 & 206.78 & 5.43 & 2.77 \\
\hline 4A & 25 & 174.01 & 176.05 & 156.24 & 186.44 & 7.77 & 4.46 \\
\hline
\end{tabular}

Table 7. Shapiro-Wilk test $\mathrm{W}$ and $\mathrm{p}$ value of hardness test results from the Hs scratch test

\begin{tabular}{|c|c|c|}
\hline Group (material) & W & p \\
\hline 1A & 0.9672 & 0.5739 \\
\hline 2A & 0.9004 & 0.1872 \\
\hline 3A & 0.9611 & 0.4362 \\
\hline 4A & 0.9350 & 0.1135 \\
\hline
\end{tabular}

Table 8. Results of variance homogeneity tests

\begin{tabular}{|c|c|c|c|c|}
\hline \multicolumn{7}{|c|}{ Test Levene } \\
\hline Source of variance & MS - Effect & MS Error & F & $\mathrm{p}$ \\
\hline Group (material) & 63.0576 & 9.4877 & 6.6462 & 0.0004 \\
\hline \multicolumn{7}{|c|}{ Brown-Forsythe } & F & $\mathrm{p}$ \\
\hline Source of variance & MS - Effect & MS Error & 5.1393 & 0.0024 \\
\hline Group (material) & 60.1414 & 11.7022 & & \\
\hline
\end{tabular}

Table 9. Results of Tukey test

\begin{tabular}{|c|c|c|c|c|}
\hline Groups (materials) & $\{1\}-\mathbf{M}=\mathbf{1 6 6 . 4 5}$ & $\{\mathbf{2}\}-\mathbf{M}=\mathbf{1 7 2 . 7 7}$ & $\{\mathbf{3}\}-\mathbf{M}=\mathbf{1 9 6 . 1 2}$ & $\{\mathbf{4}\}-\mathbf{M}=\mathbf{1 7 4 . 0 1}$ \\
\hline 1A $\{1\}$ & & 0.0005 & 0.0001 & 0.0002 \\
\hline 2A $\{2\}$ & 0.0005 & & 0.0001 & 0.8497 \\
\hline 3A $\{3\}$ & 0.0001 & 0.0001 & & 0.0001 \\
\hline 4A $\{4\}$ & 0.0001 & 0.8497 & 0.0001 & \\
\hline
\end{tabular}

of scratch hardness measurements are indicated by the values of significance of $p$ differences. Values of $\mathrm{p}$ below the assumed level $(p<0.05)$ indicate significant differences in the scratch hardness of the tested materials (Table 5). The values indicating significant differences are marked in red. Post hoc test results indicate no significant differences for $2 \mathrm{~A}$ and $4 \mathrm{~A}$ materials.

\section{DISCUSSION}

Thegosis and bruxism, can also result in friction and wear from orthodontic appliances. Thegosis is the action of sliding teeth into lateral positions [46]. This has been suggested to be a genetically determined habit originally established to sharpen teeth $[46,47]$. Bruxism is the action of grinding teeth without the presence of food, which is regarded as a response to stress and treated clinically as pathological behavior $[46,48]$. Orthodontic appliances that serve to prevent the effects of these diseases should take over these pathological forces and movements, relieving teeth without losing functionality during their use by the patient. The measures that determine the functional quality of orthodontic appliances include hardness [49] and wear resistance [23].

The hardness of materials is particularly important for structures in which contact stresses occur $[50,51]$. The highest Shore hardness among the tested materials was material $1 \mathrm{~A}$. Although the differences in the Shore hardness of the examined materials were insignificant, the post hoc test showed that the hardness of material 1, which was the hardest, was statistically significantly 
different from material $2 \mathrm{~A}$, which had the lowest hardness (Table 5). Material 2A showed the highest Shore hardness and, at the same time, the lowest scratch coefficient of friction (SCOF) [52] (Fig. 6). In [44] it was stated that a correlation of friction coefficient with hardness was found for some polymers. This means that observations in this direction have already been carried out and this conclusion can be justified. The scratch hardness $(H s)$ results presented in the paper point to different relationships between the tested materials and those obtained using the Shore method. The highest $H s$ hardness among the tested materials was characteristic for material $1 \mathrm{~A}$. Also post hoc tests show larger statistically significant differences in $H s$ hardness of the tested materials. Statistically significant differences were not found only for materials $2 \mathrm{~A}$ and $4 \mathrm{~A}$. It should be noted that the $H s$ value depends on the width of the SW crack remaining after unloading the sample. Researchers point out that scratch hardness is a method that gives different results from indentation hardness tests [53]. Shore's hardness depends on the depth of the needle's recess in the tested material, and it is likely that the dissimilarity of the measuring methods results in a different ranking in the hardness of the tested materials. However, the scratch hardness method is recognized and often used, which is reflected in technical standards [54]. The result obtained by this method is all the more important because surface scratches are an immanent feature of polymer parts of orthodontic appliances.

For many materials, it is declared that the material is scratch resistant. It is not obvious why the material is scratch resistant. Only an objective methodology based on the principles of material engineering allows for unambiguous assessment [52]. Unfortunately, most polymer materials are susceptible to scratch damage [52]. The Committee of the Institution of Mechanical Engineers defined wear as "the progressive loss of substance from the surface of a body brought about by mechanical action" [55]. It seems that in the case of tooth edge contact, which is much harder than the polymer material of orthodontic appliances, abrasive wear may be the most important. In [34] the case of abrasive wear of polymers was determined - abrasive wear is caused by hard asperities on the counterface, which dig into the friction surface of the polymer and remove material, resulting in micro-machining, wear grooves, tearing, ploughing, scratching.
Scratching in the friction direction is an evidence of abrasion wear of polymers [56]. Observations, terminology and definitions contained in the papers [32, 55, 56], as well as others, incl. [57], are the most appropriate in relation to scratch damage of polymers used to orthodontic appliances. In the research whose results were presented in this article, material $1 \mathrm{~A}$ was characterized by the lowest residual after scratch test $(R d)$ consumption. At the same time, the same material showed the lowest coefficient of friction. It is possible that such properties of $1 \mathrm{~A}$ material are related to the content in the structure of this polymer material of the component that acts as a slip agent [58]. In [59] it was observed that the incorporation of slip agents to thermoplastic olefin resulted in a significant decrease in the sliding friction coefficient during scratching, thus improving the scratch resistance. In $[60,61]$ it was noted that in polymers that contain a slip agent component, it tends to migrate to the surface of the polymer, forming a waxy layer that lowers the friction coefficient. It is possible that this factor determined the good scratch resistance of 1A material.

\section{CONCLUSIONS}

Based on the study of literature and research, the following conclusions were made:

1. Despite the fact that only PMMA organic polymers were tested, the resistance of the surface layer of these materials is varied. They depend more on the particular technology used than on the material itself. The material 1A had the highest Shore hardness (80.38 ShD). It is a material containing methacrylic oligomers, unlike the $2 \mathrm{~A}$ material with the lowest Shore hardness (78.02 ShD), which is entirely based on polymethylmethacrlat (PMMA).

2. It seems that the application of scratch tests allowed to show the differences between the tested materials to a greater extent. It should be emphasized that the most beneficial properties due to the depth of residual surface damage were obtained in the case of $1 \mathrm{~A}$ material. Values of scratch residual depth $(R d)$ were correlated with Shore's hardness.

3. The scratch hardness depends on the SW crack width, due to this measure the best results were obtained for 3A material (196.12 MPa). The second material with the highest scratch 
hardness was 4A(174.01 MPa). Both materials (3A, 4A) have a similar composition but are distinguished by the color. These are the most complex materials among the respondents. The material 1A (166.45 MPa) with the lowest Rd had the lowest scratch hardness .

\section{REFERENCES}

1. Gómez-Mascaraque, L.G., Palao-Suay, R., Vázquez, B. The use of smart polymers in medical devices for minimally invasive surgery, diagnosis, and other applications, In Woodhead Publishing in Materials, Smart Polymers and their Applications (Second Edition); Aguilar, M.R., San Román, J., Eds.; Woodhead Publishing, Sawston, Cambridge, UK, 2019, pp. 481-531.

2. Lamprou, D.A., Scoutaris, N., Ross, S.A., Douroumis, D. Polymeric coatings and their fabrication for medical devices, In Encyclopedia of Biomedical Engineering; Narayan, R., Ed.; Elsevier, Cambridge, USA, 2019, pp. 177-187.

3. Chopra, A.M., Mehta, M., Bismuth, J., Shapiro, M., Fishbein, M.C., Bridges, A.G., Vinters, H.V. Polymer coating embolism from intravascular medical devices - a clinical literature review. Cardiovasc. Pathol. 2017, 30, 45-54.

4. Pieniak, Daniel Wit-Rusiecki, Albin M Krzyżak, Aneta Gil, Leszek Krzysiak, Zbigniew: Adhesion tests of varnish coatings used on the surface of carbon fiber reinforced polimer compositions. Przemysł Chemiczny, 98(10), 1619-1622.

5. Świderski, A.; Borucka, A.; Grzelak, M.; Gil, L. Evaluation of Machinery Readiness Using SemiMarkov Processes. Appl. Sci. 2020, 10, 1541.

6. Tipnis, N.P., Burgess, D.J. Sterilization of implantable polymer-based medical devices: A review. Int. J. Pharm. 2018, 544, 455-460.

7. Kuczko, W., Wichniarek, R., Górski, F., Banaszewski, J. Influence of Sterilization of a Product Manufactured Using FDM Technology on its Dimensional Accuracy. Adv. Sci. Technol. Res. J. 2018, 12, 74-79.

8. Łępicka, M., Grądzka-Dahlke, M. Surface Analysis for Signs of Corrosion of Fixed Orthodontic Appliances Used In Vivo. Adv. Mater. Sci. 2016, 16, 5-14.

9. Klimek, L., Palatyńska-Ulatowska, A. Scanning electron microscope appearances of fretting in the fixed orthodontic appliances. Acta. Bioeng. Biomech. 2012, 14, 79-83.

10. Shepherd, D.E.T.; Dearn, K.D. Wear processes in polymer implants. In Woodhead Publishing Series in Biomaterials, Durability and Reliability of Medical Polymers; Jenkins, M., Stamboulis, A., Eds.; Woodhead Publishing, Sawston, Cambridge, UK, 2012, pp. 143-163.
11. Lewis, P.R. The failure of synthetic polymeric medical devices. In Woodhead Publishing Series in Biomaterials, Durability and Reliability of Medical Polymers; Jenkins, M., Stamboulis, A., Eds.; Woodhead Publishing, Sawston, Cambridge, UK, 2012, pp. 183-224.

12. Lewis, P.R. Manufacturing defects in polymeric medical devices. In Woodhead Publishing Series in Biomaterials, Durability and Reliability of Medical Polymers; Jenkins, M., Stamboulis, A., Eds.; Woodhead Publishing, Sawston, Cambridge, UK, 2012, pp. 225-268.

13. Karthick, R., Sirisha, P., Ravi Sankar, M. Mechanical and Tribological Properties of PMMA-Sea Shell based Biocomposite for Dental application. Procedia Mater. Sci. 2014, 6, 1989-2000.

14. Pieniak, D.; Walczak, A.; Niewczas, A.M.; Przystupa, K. The Effect of Thermocycling on Surface Layer Properties of Light Cured Polymer Matrix Ceramic Composites (PMCCs) Used in Sliding Friction Pair. Materials 2019, 12, 2776.

15. Górski, F., Wichniarek, R., Kuczko, W., Burdzińska, M., Jankowska, M. Mechanical properties of parts of medical products produced using additive manufacturing technologies. Adv. Sci. Technol. Res. J. 2017, 11, 166-171.

16. Walczak, A., Niewczas, A., Pieniak, D., Gil, L., Kozłowski, E., \& Kordos, P. (2018). Temporary Stability of Compressive Strength of Flow and Universal Type LC PMCCS Materials. Advances in Materials Science, 18, 22-33.

17. Gil, L., Pieniak, D., Walczak, M., Ignaciuk, P., \& Sawa, J. (2014). Impact of acid number of fuels on the wear process of apparatus for fuel injection in diesel engines. Advances in Science and Technology Research Journal, 8(21), 54-57.

18. Ignaciuk, P., \& Gil, L. (2014). Damages to injectors in diesel engines. Advances in Science and Technology Research Journal, 8(21), 58-61.

19. Szala M, Hejwowski T, Lenart I. Cavitation erosion resistance of $\mathrm{Ni}-\mathrm{Co}$ based coatings. Advances in Science and Technology Research Journal, 2014, 8(21), 36-42. doi:10.12913/22998624.1091876.

20. Szala, M., Szafran, M., Macek, W., Marchenko, S.V., \& Hejwowski, T. (2019). Abrasion Resistance of S235, S355, C45, AISI 304 and Hardox 500 Steels with Usage of Garnet, Corundum and Carborundum Abrasives. Advances in Science and Technology Research Journal, 13, 151-161.

21. Żebrowski, R., Walczak, M., Korga, A., Iwan, M., \& Szala, M. (2019). Effect of Shot Peening on the Mechanical Properties and Cytotoxicity Behaviour of Titanium Implants Produced by 3D Printing Technology. Journal of Healthcare Engineering, 2019.

22. Pieniak, D.; Przystupa, K.; Walczak, A.; Niewczas, A.M.; Krzyzak, A.; Bartnik, G.; Gil, L.; Lonkwic, 
P. Hydro-Thermal Fatigue of Polymer Matrix Composite Biomaterials. Materials 2019, 12, 3650.

23. Pieniak, D.; Walczak, A.; Walczak, M.; Przystupa, K.; Niewczas, A.M. Hardness and Wear Resistance of Dental Biomedical Nanomaterials in a Humid Environment with Non-Stationary Temperatures. Materials 2020, 13, 1255.

24. Łępicka, M.; Grądzka-Dahlke, M.; Pieniak, D.; Pasierbiewicz, K.; Niewczas, A. Effect of mechanical properties of substrate and coating on wear performance of TiN- or DLC-coated 316LVM stainless steel. Wear 2017, 382-383, 62-70.

25. Łępicka, M.; Grądzka-Dahlke, M.; Pieniak, D.; Pasierbiewicz, K.; Kryńska, K.; Niewczas, A. Tribological performance of titanium nitride coatings: A comparative study on TiN-coated stainless steel and titanium alloy. Wear 2019, 422-423, 68-80.

26. Lin, C., Chung, C., Chou, C., He, J. In vitro wear tests of the dual-layer grid blasting-plasma polymerized superhydrophobic coatings on stainless steel orthodontic substrates. Thin Solid Films 2019, 687, 137464.

27. Pieniak, D., Gauda, K. Indentation Hardness and Tribological Wear in Conditions of Sliding Friction of the Surface Layer of Composites Based on Methacrylate Resins with Ceramic Nanofiller. Adv. Sci. Technol. Res. J. 2020, 14, 112-119.

28. Leggat, P.A., Smith, D.R., Kedjarune, U. Surgical applications of methyl methacrylate: a review of toxicity Arch. Environ. Occup. Health 2009, 64, 207-212.

29. Münker, T.J., Vijfeijken, S.E., Mulder, C.S., Vespasiano, V., Becking, A.G., Kleverlaan, C.J., Dubois, L., Karssemakers, L.H., Milstein, D.M., Depauw, P.R., Hoefnagels, F.W., Vandertop, W.P., Maal, T.J., Nout, E., Riool, M., \& Zaat, S.A. Effects of sterilization on the mechanical properties of poly(methyl methacrylate) based personalized medical devices. J. Mech. Behav. Biomed. 2018, 81, 168-172 .

30. Almaraz, G.M., Martínez, A.G., Sánchez, R.H., Gomez, E., Tapia, M., \& Juárez, J. Ultrasonic fatigue testing on the polymeric material PMMA, used in odontology applications. Procedia Struct. Integrity $2017,3,562-570$.

31. Nowakowska-Toporowska, A., Malecka, K., Raszewski, Z., Wieckiewicz, W. Changes in hardness of addition polymerizing silicone resilient denture liners after storage in artificial saliva. J. Prosthet. Dent. 2019, 121, 317-321.

32. Hirai, K., Ikawa, T., Shigeta, Y., Shigemoto, S., Ogawa, T. Evaluation of sleep bruxism with a novel designed occlusal splint. J. Prosthodont. Res. 2017, 61, 333-343.

33. Abdelbary, A.M. Polymer tribology. In Wear of Polymers and Composites, Abdelbary, A.M., Eds.; Woodhead Publishing, Sawston, Cambridge, UK,
2014, pp. 1-36.

34. Abdelbary, A.M. Methodology of testing in wear. In Wear of Polymers and Composites, Abdelbary, A.M., Eds.; Woodhead Publishing, Sawston, Cambridge, UK, 2014, pp. 159-183.

35. Jańczuk, Z. Stomatologia zachowawcza. Zarys kliniczny. (in polish), PZWL, Warsaw, Poland, 2008, 508.

36. Komorowska, A. Materiały i Techniki Ortodontyczne. (in polish), PTO, Warsaw, Poland, 2009, 172.

37. www.vertex-dental.com. Available online: https://www.vertex-dental.com/en/products/31en/26/151-vertex-orthoplast-shade-guide (accessed on 15 april 2020).

38. Mohamed, M.I., Aggag, G. Uncertainty evaluation of shore hardness testers. Measurement 2003, 33, 251-257.

39. Dasari, A., Rohrmann, J., Misra, R.D.K. On the scratch deformation of micrometric wollastonite reinforced polypropylene composites. Mater. Sci. Eng., A 2004, 364, 357-369.

40. Briscoe, B.J., Pelillo, E., Sinha, S.K. Scratch hardness and deformation maps for polycarbonate and polyethylene. Polym. Eng. Sci. 2003, 36, 2996-3005.

41. Godziszewski, J., Mania, R., Pampuch, R. Zasady planowania doświadczeń i opracowania wyników pomiarów. (in polish), AGH, Cracow, Poland, 1982, 407.

42. Volk, W. Applied Statistics for Engineers. Literary Licensing, LLC, Whitefish, MT, USA, 2013, 364.

43. Hill, T., Lewicki, P. Statistics: methods and applications: a comprehensive reference for science, industry and data mining. StatSoft, Inc., UK, 2006, 832.

44. Bordens, K.S., Abbott, B.B. Research Design and Methods. A Process Approach. McGraw-Hill, New York, USA, 2018, 624.

45. Blau, P.J. The significance and use of the friction coefficient. Tribol. Int. 2001, 34, 585-591.

46. Zhou, Z., Zheng, J. Tribology of dental materials: a review. J. Phys. D: Appl. Phys. 2008, 41, 113001.

47. Every, R.G., Kuhne, W.G., Kermack, D.M., Kermack, K.A. Bimodal Wear of Mammalian Teeth. early Mammals. Zool. J. Linn. Soc. 1971, 50, 23-27.

48. Mair, L.H., Stolarski, T.A., Vowles, R.W., Loyd C.H. Wear: mechanisms, manifestations and measurement Report of a workshop. J. Dentistry 1996, 24, 141-148.

49. Pieniak, D., Niewczas, A.M., Kordos, P. Influence of thermal fatigue and ageing on the microhardness of polymer-ceramic composites for biomedical applications. Eksploatacja i Niezawodnosc, 2012, 14 (2), 181-188.

50. Kajdas, C., Kulczycki, A., Ozimina, D. A new concept of the mechanism of tribocatalytic reactions 
induced by mechanical forces. Tribol. Int. 2017, 107, 144-151.

51. Gałuszka, G., Madej, M., Ozimina, D., Kasińska, J., Gałuszka, R. The characterisation of pure titanium for biomedical applications. Metalurgija 2017, 56, 191-194.

52. Browning, R.L., Jiang H., Sue, H.-J. Scratch behavior of polymeric materials. In Tribology of Polymeric Nanocomposites, Friedrich K., Schlarb, A.K., Eds.; Butterworth-Heinemann, Oxford, UK, 2013, pp. 513-550.

53. Myshkin, N.K., Petrokovets, M.I., \& Kovalev, A.S. Tribology of polymers: Adhesion, friction, wear, and mass-transfer. Tribol. Int. 2005, 38, 910-921.

54. ASTM G171 - Standard test method for scratch hardness of materials using a diamond stylus; ASTM International, West Conshohocken, PA, USA, 2003.

55. Glossary of terms and definitions in the field of friction, wear and lubrication (tribology). Wear 1970, 15,456 .
56. Abdelbary, A.M. Wear of polymers in wet conditions. In Wear of Polymers and Composites, Abdelbary, A.M., Eds.; Woodhead Publishing, Sawston, Cambridge, UK, 2014, pp. 95-112.

57. Rymuza, Z. Tribology of Polymers, Arch Civ Mech Eng 2007, 7, 177-184.

58. Dasari, A., Yu, Z., Mai, Y. Wear and scratch damage in polymer nanocomposites. In Tribology of Polymeric Nanocomposites, Friedrich K., Schlarb, A.K., Eds.; Butterworth-Heinemann, Oxford, UK, 2013, pp. 551-570.

59. Browning, R., Lim, G.T., Moyse, A., Sun, L., Sue, $H$. Effects of slip agent and talc surface-treatment on the scratch behavior of thermoplastic olefins. Polym. Eng. Sci. 2006, 46, 601-608.

60. Rawls, A.S., Hirt, D.E., Havens, M.R., \& Roberts, W.P. Evaluation of surface concentration of erucamide in LLDPE films., J. Vinyl. Addit. Techn. 2002, 8, 130-138.

61. Edenbaum, J. Plastics Additives and Modifiers Handbook. Chapman \& Hall, London, UK, 1996, 1136. 